\title{
Economic Costs of Lung Cancer in China
}

\author{
Shaoyu Fan ${ }^{1}$, Zhengzhong Mao ${ }^{1}$, Anita $\mathrm{H} \mathrm{Lee}^{2}$ and Teh-wei Hu, ${ }^{2,3^{*}}$
}

${ }^{1}$ Sichuan University, Huaxi School of Public Health, Chengdu, China

${ }^{2}$ The Public Health Institute, Oakland, CA, USA

${ }^{3}$ University of California School of Public Health, Berkeley, CA, USA

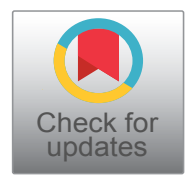

*Corresponding author: Teh-wei Hu, University of California, Berkeley, School of Public Health, Berkeley California 94720, USA

\begin{abstract}
Background: Lung cancer is the leading cause of mortality in China. In 2015, China recorded 610,200 lung cancer deaths.

Objectives: The objective of this paper is to estimate the economic costs of lung cancer in China.

Methods: The economic costs of lung cancer include direct medical costs, direct non-medical costs, indirect morbidity costs, and indirect mortality costs. Indirect morbidity and mortality costs (loss of productivity to the society) are estimated using the human capital approach. Six cities in China were selected to represent the country's economic and geographic distribution. The study sample includes 1,244 lung cancer patients randomly selected from major Chinese hospitals in 2014-2015.
\end{abstract}

Results: The estimated total national medical cost of treating lung cancer patients in China was 64.21 billion RMB (US\$ 10.31 billion), about $2 \%$ of total medical costs in 2015 . Total lung cancer costs in 2015 were 488.53 billion RMB (US $\$ 78.42$ billion), about $75 \%$ of which can be attributed to mortality costs.

Discussions: Two-thirds of the lung cancer patients in the sample were either current or former smokers. The major economic costs of lung cancer among smokers are preventable. China has a relatively low cigarette tax rate. Raising the tobacco tax and engaging in other tobacco control programs not only would reduce future lung cancer patient incidence, thus will also reduce lung cancer costs in China.

\section{Keywords}

Costs, Lung cancer, China

\section{Introduction}

Lung cancer is a leading cause of mortality in China [1]. In 2015, lung cancer caused the deaths of 610,200 people: 432,400 men and 177,800 women [2]. The lung cancer mortality rate in China is 49.4 per 100,000 [3].

Patients diagnosed with lung cancer require costly medical services as well as services from their caregivers. In addition, premature deaths from lung cancer result in a loss of productivity to society. The purpose of this study is to estimate the economic costs of lung cancer in China. Understanding the magnitude of these economic costs will provide government policymakers with information to better evaluate competing demands for the use of scarce health care resources for prevention, treatment, and care services, and help them determine resource allocation priorities.

\section{Methods}

The economic costs of lung cancer have two components: direct costs and indirect costs. Direct costs refer to the values of services used to treat lung cancer patients; they include physician services, hospital stays, medications, and social/home care services. Indirect costs refer to the value of resources lost due to lung cancer; they include, among other things, loss of productivity due to morbidity and mortality. The sum of the direct costs and indirect costs of lung cancer determines the total economic burden on a society.

This study first identified a sample of diagnosed lung cancer patients from health care providers and recorded their use of various services, such as outpatient visits and inpatient days, type and amount of medications, and nursing care expenses. In addition, direct non-medical costs are incurred related to medical treatment, such as travel expenses for the patients and patient caregivers,

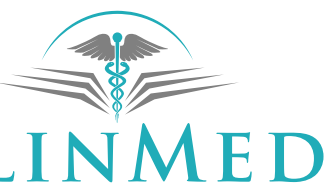

INTERNATIONAL LIBRARY

Citation: Fan S, Mao Z, Lee AH, Teh-wei H (2018) Economic Costs of Lung Cancer in China. Int J Oncol Res 1:007.

Accepted: September 27, 2018; Published: September 29, 2018

Copyright: (C) 2018 Fan S, et al. This is an open-access article distributed under the terms of the Creative Commons Attribution License, which permits unrestricted use, distribution, and reproduction in any medium, provided the original author and source are credited. 
nutritional supplements, and room and board expenses.

To estimate the indirect costs of morbidity, data were collected from patients and their caregivers about their time lost from employment and years of premature death. The loss of productivity can be estimated in monetary value by imputing average earnings by age, gender, and urban/rural locations. This method of estimation is called the human capital approach. To convert these future earnings into present value, a $3 \%$ discount rate is used as an international standard [4].

\section{Data Sources}

Given the size of China and a limited interview survey budget, the study team identified six cities representative of the economic and geographic distribution of the country: Nanjing and Hangzhou for the east region, Nanchang for the central region, Chongqing and Wulumuqi for the western region, and $\mathrm{Ha}$ 'er bing for the northern region. The China National Cancer Center estimated 973,701 lung cancer patients in 2015 [2]. An adequate sample size for estimating the overall cost of lung cancer patients with a $5 \%$ margin of error and a $99 \%$ confidence interval was determined as a minimum of 666 lung cancer patients [5]. To increase the statistical power of prediction, the study decided to recruit about 1,200 lung cancer patients among the six selected cities. In each city, around 200 lung cancer patients (diagnosed from ICD-10) were selected randomly from cancer hospitals or major general hospitals with an oncology department. A total of 1,255 first time-diagnosed lung cancer patients who had been discharged from the subject hospitals were selected randomly to participate in the survey. Interviewers obtained a consent agreement to follow up with the patients' caregivers for personal interviews.

\section{Results}

Data were collected from 1,255 patients during a two-year period (2014-2015). Excluding patients with missing key data items, 1,224 lung cancer patients completed the survey (97.53\%). Table 1 shows the distribution of the study sample among the six cities (Table 1 ).

Table 2 provides a description of the sociodemographic characteristics of the 1,224 patients who completed the survey. About $72 \%$ of the lung cancer patients in the sample are male. The large proportion of male patients is due to the high percentage $(52 \%)$ of males in China who are smokers as compare to $3 \%$ of females are smokers [1]. Within the study sample, 800 (65\%) of the total sample are smokers (either former or current), and 424 (35\%) are nonsmokers.

Forty percent (40\%) of the sample is less than 60 -years-old, about $60 \%$ of the study subjects have an education of less than junior high school; $40.6 \%$ incurred lung cancer less than a year prior to the survey, $54.9 \%$ had lung cancer between one and two years pri-
Table 1: Sample Distribution among Six Cities $(n=1,224)$.

\begin{tabular}{|l|l|l|}
\hline Cities & Sample Size & $\%$ \\
\hline Hangzhou & 223 & 18 \\
\hline Nanjing & 209 & 17 \\
\hline Nanchang & 199 & 17 \\
\hline Ha'erbing & 195 & 16 \\
\hline Wulumuqi & 200 & 16 \\
\hline Chongqing & 198 & 16 \\
\hline
\end{tabular}

Table 2: Sociodemographic Characteristics of Study Sample $(n=1,224)$.

\begin{tabular}{|c|c|c|c|}
\hline Variables & $\begin{array}{l}\text { Total Sample } \\
(\%)\end{array}$ & Variables & $\begin{array}{l}\text { Total } \\
\text { Sample } \\
(\%)\end{array}$ \\
\hline Gender & & $\begin{array}{l}\text { Income (RMB/ } \\
\text { Month) }\end{array}$ & \\
\hline Male & 72.5 & $<2000$ & 49.1 \\
\hline Female & 27.5 & $2000-4999$ & 48.7 \\
\hline Age & & $5000-10000$ & 1.4 \\
\hline $25-60$ & 40.7 & $>10000$ & 0.8 \\
\hline$>60$ & 59.3 & Health Insurance & \\
\hline Smoker Status & & Worker Insurance & 51.4 \\
\hline Smoker & 65 & Farm Insurance & 27.9 \\
\hline Non-Smoker & 35 & Urban Resident & 2.1 \\
\hline Marital Status & & Commercial & 10.7 \\
\hline Single & 1.1 & Public Insurance & 7.3 \\
\hline Married & 90.9 & Others & 0.5 \\
\hline Divorced & 1.6 & Employment & \\
\hline Widowed & 6.4 & Employed & 23.5 \\
\hline Education & & Retired & 58.9 \\
\hline $\begin{array}{l}\text { Junior High or } \\
\text { Less }\end{array}$ & 62.5 & Unemployed & 17.6 \\
\hline High School & 15.1 & Duration of Illness & \\
\hline $\begin{array}{l}\text { Vocational } \\
\text { School }\end{array}$ & 8.3 & $<1$ & 40.6 \\
\hline College ( 2 years a) & 7.9 & $1-2$ years & 54.9 \\
\hline $\begin{array}{l}\text { College } \\
\text { Graduate }\end{array}$ & 6.2 & $>2$ years & 4.5 \\
\hline Occupation & & Types of Hospital & \\
\hline Professionals & 45 & Local Hospital & 9.4 \\
\hline Retailer & 3.3 & $\begin{array}{l}\text { Major Urban } \\
\text { Hospital }\end{array}$ & 55.3 \\
\hline $\begin{array}{l}\text { Non-agricultural } \\
\text { workers }\end{array}$ & 21.1 & Special Hospital & 35 \\
\hline $\begin{array}{l}\text { Non-farm } \\
\text { workers }\end{array}$ & 7.9 & Others & 0.6 \\
\hline Farmers & 16.2 & & \\
\hline Other & 6.7 & & \\
\hline $\begin{array}{l}\text { a US } \$=6.23 \\
\text { RMB in } 2015\end{array}$ & & & \\
\hline
\end{tabular}

or, and $4.5 \%$ had lung cancer for two years or longer. Chi-square tests show that all subgroups classifications in Table 2 are statistically significant $(p<0.01)$ (Table 2).

A cost survey questionnaire was developed based on a study of the economic costs of depression in China [6]. Interviewers also requested patients' payment receipts and hospital records.

\section{Direct costs per lung cancer patient}

Table 3 provides direct medical costs per patient 
Table 3: Direct Cost of Lung Cancer per Patient in 2015 (in $\mathrm{RMB}^{1}$ ).

\begin{tabular}{|l|l|l|}
\hline Cost & Average & $\%$ \\
\hline Direct Medical Cost & & \\
\hline Outpatient & 5,809 & 9.1 \\
\hline Inpatient & 42,186 & 66.3 \\
\hline Medication & 11,898 & 18.7 \\
\hline Caregiver & 1,693 & 2.7 \\
\hline Direct Medical Subtotal & 61,586 & 96.7 \\
\hline Non-medical Care Cost ${ }^{2}$ & & \\
\hline Outpatient & 280 & 0.4 \\
\hline Inpatient & 1,810 & 2.8 \\
\hline Non-medical Care Subtotal & 2,089 & 3.2 \\
\hline Total Direct Cost & & 100 \\
\hline
\end{tabular}

${ }^{1} \mathrm{US} \$=6.23 \mathrm{RMB} ;{ }^{2}$ Transportation cost; food, nutrition supplements and others.

in 2015, including direct medical care costs and direct non-medical costs. The total direct costs were 63,675 RMB (US\$10,221, one US\$ = 6.23 RMB in 2015) per lung cancer patient. These costs included the insurance program payments plus individual out-of-pocket expenses estimated at the 2015 price level. On average, patients in the study sample had 5 outpatient visits and 18 inpatient days during the 12-month period studied. Smoking lung cancer patients incurred higher direct medical care costs under each of the medical service categories, including outpatient, inpatient, medication, and nursing care expenses. Direct medical costs for smoking lung cancer patients were 61,586 RMB (US\$9,885). These direct treatment costs constitute $96.7 \%$ of total direct medical costs. Direct non-medical care costs also are incurred, especially for rural patients. These direct non-medical costs include transportation costs, food/ board expenses, nutritional supplement expenses, and other costs, and they account for $3.2 \%$ of the total direct costs for both smoking and nonsmoking lung cancer patients (Table 3).

These reported total direct costs include the out-ofpocket costs and costs paid by the insurance program. The survey data show that $20 \%$ of outpatient costs, $1,162 \mathrm{RMB}(5,809 \mathrm{RMB} \times 0.2)$, and $50 \%$ of inpatient costs, $21,093 \mathrm{RMB}(42,186 \mathrm{RMB} \times 0.5)$, are reimbursed by patients' insurance programs. In other words, the total cost of out-of-pocket expenses per lung cancer patient would be 22,255 RMB (US\$ 3,572).

According to the China Statistical Yearbook 2016, [7], the average disposable income in China in 2015 was 10,772 RMB (US\$ 1,729) per rural resident and 31,195 RMB (US\$ 5,007) per urban resident. Comparing the average income per person with the out-of-pocket costs of lung cancer patients reveals that the out-of-pocket cost of lung cancer represents two times the annual income of rural patients and $70 \%$ of the income of urban patients. Thus, having lung cancer places a very heavy economic burden on Chinese families.
Table 4: Indirect Morbidity Cost of Lung Cancer per Patient in 2015 (in $\mathrm{RMB}^{1}$ ).

\begin{tabular}{|l|l|l|}
\hline & Average & $\%$ \\
\hline Time lost from work & 4,078 & 7.3 \\
\hline Income lost by caregivers & 50,380 & 87.3 \\
\hline Time lost by visitors & 3,237 & 5.4 \\
\hline Total & 57,695 & 100 \\
\hline
\end{tabular}

${ }^{1} \mathrm{US} \$=6.23 \mathrm{RMB} ;{ }^{2}$ Transportation cost; food; nutrition supplements and other.

\section{Estimated national direct costs of lung cancer}

One method to estimate the national economic cost of lung cancer is to adopt a bottom-up approach, which identifies a sample of diagnosed patients and records their use of various services and expenditures. Based on costs per lung cancer patient in the sample $(63,675$ $\mathrm{RMB})$, together with disease prevalence rates $(973,701$ lung cancer patients), a total national cost of lung cancer is projected. The total national direct medical costs (excluding direct non-medical costs) for lung cancer patients in 2015 were 64.21 billion RMB (US\$ 10.31 billion). The total national medical expenditure during 2015 was 3,250 billion RMB (US\$ 522 billion), which represents $2 \%$ of total Chinese national medical costs [1].

\section{Estimated indirect morbidity costs of lung cancer}

The indirect costs of lung cancer include productivity and morbidity loss due to illness. Three types of work time may be lost due to lung cancer: (1) Work time lost by patients while staying in the hospital and going to doctor visits; (2) Work time lost by family members who are caregivers and (3) Work time that visitors spend with patients. The survey data show that patients' work time lost and workload reduction resulting from hospital stays and doctor visits was about 250 work hours (about 31 days) in 2015. Non-paid family members all together spent about 3100 hours (about 380 days) taking care of the lung cancer patients in the study. Visitors spent about 200 hours (about 25 working days) with patients. This study uses the lost earnings as a measure of lost productivity. Using the reported national average wage rate for rural workers, urban workers, and retired workers in China, Table 4 provides the estimated indirect morbidity costs of lung cancer patients. The estimated total indirect morbidity cost was 57,695 RMB (US\$ 9,260) for lung cancer patients. The large majority of indirect morbidity costs are lost income of caregivers, which represents about $87 \%$ of the total indirect non-medical costs. The remainder of the cost, $13 \%$, is the lost time incurred by patients and their visitors (Table 4).

Combining the direct costs $(63,675 \mathrm{RMB})$ and indirect morbidity costs $(57,695 \mathrm{RMB})$ per lung cancer patient in 2015 results in a total economic cost of 121,370 RMB (US\$19,481) per patient. Direct medical costs represent a higher proportion of the total costs than the indirect morbidity cost. 
Table 5: Total Economic Cost among Lung Cancer in China 2015 (in billion RMB).

\begin{tabular}{|l|l|l|}
\hline & Total $(\mathbf{n}=\mathbf{9 8 3}, \mathbf{6 7 8})$ & \% \\
\hline Direct cost & 64.21 & 13 \\
\hline Morbidity cost & 55.67 & 12 \\
\hline Mortality cost & 368.65 & 75 \\
\hline Total Cost & 488.53 & 100 \\
\hline
\end{tabular}

\section{Estimated indirect mortality costs of lung cancer}

To determine the monetary value of premature death as a result of lung cancer requires a life table, remaining life expectancy, yearly earnings, and expected employment rate at a given age. The average expected life span in China in 2015 was 76.34 years. According to the China Health and Population Planning Yearbook 2016 [1], the potential combined years of life lost (PYLL) for lung cancer patients are 5.5 million-person years. According to the China Statistical Yearbook 2016, [7], given the per capita annual income in 2015 and the estimated number of lung cancer patients, with a $3 \%$ discount rate and a projected $2 \%$ growth of per capita income, the total value of premature deaths in China in 2015 due to lung cancer was 368.65 billion RMB (US\$ 59.17 billion), as shown in Table 5 .

\section{Estimated national economic cost of lung cancer}

As shown in earlier section, Estimated National Direct Costs, the total national direct cost of lung cancer was 64.21 billion RMB. The estimated per lung cancer patient indirect morbidity cost was $57,695 \mathrm{RMB}$. With 973,701 lung cancer patients in 2015 , the estimated total national morbidity cost was 55.67 billion RMB, as shown in Table 5. Together with the estimated indirect mortality cost of lung cancer 368.65 billion RMB, the total national cost of lung cancer in China was 488.53 billion (US\$ 78.42 billion). As shown in Table 5, about $75 \%$ of these costs are attributable to mortality costs and premature death, followed by the direct medical costs of $13 \%$, and the morbidity cost of $12 \%$ cost.

\section{Discussion}

Between 1990 and 2014, lung cancer was the leading cause of illness and the leading cause of cancer deaths in China. The illness has resulted in an increased use of medical resources, and rising expenses and time loss to families and caregivers, as well as the productivity loss due to premature deaths. Direct lung cancer treatment costs consume a large proportion of families' entire annual household income. With the increasing cost of health care in recent years in China, the economic burden of lung cancer patients will become even more serious in the future.

Smoking is a leading cause of lung cancer. As shown in the paper, two-thirds of lung cancer patients are either former smokers or current smokers. It also should be noted that the major economic costs of lung cancer among smokers are preventable. If the government engages in tobacco control programs, such as legislating smoke-free policies in public places, enlarging the warning label on cigarette packages, and raising the tax on cigarettes, China can reduce its consumption of cigarettes, and subsequently, reduce the major economic costs of lung cancer. China has a relatively low cigarette tax rate, about $56 \%$ of the retail price, which is less than the World Health Organization's guideline of $70 \%$ of the retail price [8]. Raising the cigarette tax has been shown to be one of the most effective tobacco control policy instruments. Therefore, increasing the tobacco tax would not only reduce the future lung cancer costs, but also save lives in China.

In addition to smoking, air pollution are also known to be associated to lung cancer mortality [9]. Thus, recent Chinese government effort to reduce urban air pollution would help to reduce future lung cancer incidence in China.

\section{Limitations}

This study has collected detailed cost data from individual lung cancer patients and their care givers from six cities in China. Although they are representative of the economic and geographic distribution of the country, results may not be representative of entire national lung cancer patient population. Estimated lung cancer patient costs in this study can be considered as an approximation. To obtain a more representative costs estimates, it would require a national representative survey of lung cancer patients.

\section{Acknowledgement}

This study was supported by the US National Institutes of Health, Fogarty International Center and the National Cancer Institute (grant no. RO1-TW009295). The authors are grateful to the participating data collection collaborators of this study: Guoxiang Liu, Harbin University; Jianghong Rao, Nanchang University; Dongfu Qian, Nanjing Medical University; Yangjing Ou, Xingjiang University; Li Huang, Chongqing University; and Jianping Ren, Hangzhou Normal University. Thanks to Professor Lian Yang of the Chengdu Chinese Traditional Medicine University and Jing Ouyang of Sichuan University for providing helpful assistance. The content is solely the responsibility of the authors and does not necessarily represent the official view of the funding agencies.

This study was supported by the US National Institutes of Health, Fogarty International Center and the National Cancer Institute (grant no. RO1-TW009295).

\section{References}

1. (2016) China National Health and Family Planning Commission. China Health and Family Planning Statistical Yearbook, (1999-2015), Peiking Union Medical College Press, Beijing.

2. Chen W, Zheng R, Baade PD, Zhang SW, Zeng H, et al. (2016) "Cancer Statistics in China. CA: A Cancer J Clin 66: 115-132. 
3. Chen WQ, Zhang RS, Zeng HM, Zhang SW (2015) Epidemiology of Lung Cancer in China. Thorac Cancer 6: 209215.

4. Drummond M, O'Brian B, Stoddart G, Torrance G (1997) Methods for Economic Evaluation of Health Care Programs. ( $2^{\text {nd }}$ edn), Oxford University Press.

5. Goldstein R (1989) Power and Sample Size via MS/PCDOS computer. American Statistician 43: 253-260.

6. Hu T, He Y, Zhang M, Chen N (2007) "Economic Costs of Depression in China". Soc Psychiatry and Psychiatry Epidemiology 42: 110-116.
7. (2016) China National Bureau of Statistics. China Statistic Yearbook, Beijing, China.

8. World Health Organization. Regional Office for the Western Pacific, United Nations Development Programme (2017) The bill China cannot afford: health, economic and social costs of China's tobacco epidemic. Manila: WHO Regional Office for the Western Pacific, USA.

9. Chen X, Zhang LW, Huang JJ, Song FJ, Zhang LP, et al. (2016) Long-term exposure to urban air pollution and lung cancer mortality: A 12-year cohort study in Northern China. Sci. Total Environ 571: 855-861. 